\title{
Laurent Guyénot, La Lance qui saigne. Métatextes et hypertextes du «Conte du Graal» de Chrétien de Troyes
}

\section{G. Matteo Roccati}

\section{(2) OpenEdition}

1 Journals

\section{Édition électronique}

URL : http://journals.openedition.org/studifrancesi/3640

DOI : 10.4000/studifrancesi.3640

ISSN : 2421-5856

Éditeur

Rosenberg \& Sellier

\section{Édition imprimée}

Date de publication : 1 décembre 2012

Pagination : $541-542$

ISSN : 0039-2944

\section{Référence électronique}

G. Matteo Roccati, «Laurent Guyénot, La Lance qui saigne. Métatextes et hypertextes du «Conte du Graal» de Chrétien de Troyes », Studi Francesi [En ligne], 168 (LVI | III) | 2012, mis en ligne le 30 novembre 2015, consulté le 07 mars 2021. URL : http://journals.openedition.org/studifrancesi/3640 ; DOI : https://doi.org/10.4000/studifrancesi.3640

Ce document a été généré automatiquement le 7 mars 2021.

\section{(c) 9 (i) $\Theta$}

Studi Francesi è distribuita con Licenza Creative Commons Attribuzione - Non commerciale - Non opere derivate 4.0 Internazionale. 


\title{
Laurent Guyénot, La Lance qui saigne. Métatextes et hypertextes $d u$ «Conte $d u$ Graal» de Chrétien de Troyes
}

\author{
G. Matteo Roccati
}

\section{RÉFÉRENCE}

LAURENT GUYÉNOT, La Lance qui saigne. Métatextes et hypertextes du «Conte du Graal» de Chrétien de Troyes, Paris, Honoré Champion Éditeur, 2010 («Essais sur le Moyen Age», 44), pp. 344.

1 En ouverture de l'ouvrage deux affirmations annoncent le but et la logique de la démarche de l'A.: «L'objectif immédiat de cet essai est de retrouver certaines interrogations et interprétations auxquelles a pu se livrer [le] public initial» (p.9) du Conte $d u$ Graal; «La thèse de cet ouvrage est [...] l'exact contraire de celle des celtisants: je pense que les contemporains de Chrétien connaissaient et comprenaient si bien les sources du Conte $d u$ Graal qu'ils les reconnaissaient derrière la trame romanesque beaucoup mieux que nous ne pouvons le faire aujourd'hui» (p. 12).

2 La démonstration, synthèse d'une vaste bibliographie, est riche de renvois aux textes, proches ou dépendants du Conte du Graal, susceptibles de nous éclairer sur les traditions dont Chrétien s'inspire, traditions «familières» (p.12) au public auquel il s'adressait: textes en langue d'oïl (en particulier les deux premières Continuations, Le Chevalier aux deux épées, Le Bel Inconnu, Le Conte du Papegau, Le Lai de Tyolet, Le Lai d'Yonec, Perlesvaus) et textes appartenant aux domaines germanique (Lanzelet, Parzival, Wigalois, Diu Krône), anglais (Sir Orfeo, Sir Degaré, Sir Percyvell of Gales, Sir Gawain and the Green Knight) et gallois (Peredur).

3 Après les deux premiers chapitres, consacrés au Lancelot, conçu comme démarquage volontaire de deux récits, l'un de rapt et de sauvetage du monde des morts (mythe d'Orphée), l'autre christique, l'A. passe à l'étude du Perceval, contenant «selon la thèse 
de ce livre, deux discours narratifs cryptés, issus respectivement d'un imaginaire légendaire ou folklorique et d'un imaginaire christologique ou para-évangélique» (p. 14): un récit de fantôme (le Roi Pêcheur identifié au père de Perceval) demandant vengeance et le remplacement de cette dernière par un itinéraire vers la sainteté à dimension hagiographique (le Roi Pêcheur vient à désigner le Christ, qu'il faut venger par la croisade). Les deux derniers chapitres examinent la Première Continuation, témoin encore de l'arrière-plan légendaire, et le Perlesvaus, qui «perpétue une tradition d'écriture métatextuelle directement inspirée par Chrétien»(p.306); ils constatent enfin «l'effacement du métatexte légendaire du Conte du Graal dans les cycles en prose» (ibid.).

4 L'ensemble des éléments rassemblés est frappant, et on retiendra surtout, tout en nuançant peut-être le propos, que «les histoires de fantômes et de voyages chez les morts jouent dans la culture laïque du XII siècle un rôle bien plus grand qu'il n'a été jusque-là reconnu» (p. 320). On peut cependant s'interroger sur la validité générale de l'attitude polémique de l'A.: le recours à la matière de Bretagne - qu'elle soit celtique ou dans bien des cas relevant de représentations universelles (cfr. p. ex. p. 36) - déborde largement Chrétien et son autonomie, et chez Chrétien même ce recours est d'une grande variété. A côté des cohérences et des analogies mises en lumière restent des matériaux hétérogènes, ou plutôt relevant d'autres logiques, sans doute «familières» aussi au public, mais jusqu'à quel point? 